\title{
The effect of tuberositas tibia osteotomy on patellofemoral joint pressure: An experimental animal study
}

\author{
Sidar Ozturk ${ }^{1}, \quad$ Zafer Volkan Gokce ${ }^{2,3}$, Huseyin Bahadir Gokcen ${ }^{4}$, Hakki Sur $^{5}$ \\ ${ }^{1}$ Department of Orthopedics and Traumatology, Derindere Hospital, Istanbul, Turkey \\ ${ }^{2}$ Department of Orthopedics and Traumatology, Medilife Clinic, Istanbul, Turkey \\ ${ }^{3}$ Department of Orthopedic Prosthesis and Orthotics, Beykent University Vocational Health School of Higher Education, \\ Istanbul, Turkey \\ ${ }^{4}$ Department of Orthopedics and Traumatology, Istinye University, Medical Faculty, Istanbul, Turkey \\ ${ }^{5}$ Department of Orthopedics and Traumatology, Ege University, Medical Faculty, Izmir, Turkey
}

\section{ABSTRACT}

Aim: To demonstrate the decrease in patellofemoral pressure with an anterior elevation of tuberositas tibia. Therefore, we have performed Maquet's Technique to evaluate the patella pressure on femoral trochlea by biomechanically in an animal experiment model.

Methods: This study includes total of 42 knees of $21 \mathrm{New}$ Zealand rabbits. Animals were divided into two groups. The first group including 21 right knees was designated as the control group. In the second group including 21 left knees, anterior elevation of tuberositas tibia (Maquet's technique) was performed. Pressure measuring film layer "prescala" was placed on the patellofemoral joint under anesthesia in both groups. Mean values of both average and maximal pressure measurements in two groups were compared.

Results: There is a statistically significant difference in between average pressure and maximum pressure in the right and left legs of the rabbits. Average pressure and maximal pressure at rabbit knees performed Maquet's procedure were significantly lower than knees without Maquet's procedure.

Conclusion: Anterior elevation of tuberositas tibia is successful in reducing patellofemoral joint pressure which can be used in cases with patellofemoral pain syndrome non-responding to conservative treatment.

Keywords: Patellofemoral syndrome, patellofemoral pressure, tuberositas tibia, Maquet's Technique, rabbit.

$\triangle$ Dr. Sidar Ozturk

Department of Orthopaedics and Traumatology,

Derindere Hospital, Istanbul, Turkey

E-mail: sidarozturk@yahoo.com

Received: 2021-01-19

Accepted: 2021-02-06

Published online: 2021-04-01

\section{Introduction}

The prevalence of anterior knee pain (AKP) or patellofemoral pain syndrome (PFPS) has been reported as between $15-45 \%$ of the population [1]. Asymmetric formations among anatomical structures at the patellofemoral joint lead to joint discordance and thus predisposes to painful knee clinic including diseases such as osteoarthritis, PFPS and instability. PFPS is a group of symptoms especially negatively affecting the daily life of adults and leading to dysfunction [2].

PFPS is diagnosed in case of pain occurring during activities such as prolonged sitting, climbing upstairs or descending and crouching down unexplained by other pathologies. Patients with AKP are diagnosed patellar chondromalacia for many years, the softening and tissues in cartilage tissue should provide a 
diagnosis for chondromalacia. Even though their patellofemoral pain is not chondromalacia, this put them as a candidate for developing chondromalacia in the future [35]. The origin and pathogenesis of PFPS is not known precisely. However, most authors have emphasized the theory of increased patellofemoral pressure due to patellar disturbance, with patellar maltracking and dynamic valgus forces being responsible, although it is known to occur in more female patients [6-9]. Among the causes of increasing patellofemoral pressure are; posterior cruciate ligament rupture, hamstring muscle shortening, ankle dorsiflexion weakness, gastrocnemius dominance, quadriceps weakness, increased femoral anteversion, tibial external rotation, genuvalgum and varum, pes planovalgus, lateral condyle hypoplasia, patella alta and patellar subluxation [10].

There are different methods of surgical modalities described in the treatment of PFPS. These methods are; lateral reticular release, medial open wedge high tibial osteotomy and different osteotomy procedures of anterior translation of tuberositas tibia (for example dual osteotomy) [11,12]. In 1963, Maquet described anterior elevation technic of tuberositas tibia to control increased patellofemoral pressure by abnormal muscular and biomechanical factors in the pain of the anterior knee. Vector forces on patella increase the patella pressure on trochlea in case of impaired biomechanical equilibrium. Therefore, he suggested reducing patellofemoral pressure by changing only the direction of vectors, not extension forces on the patella [13].

The starting point of our study is to consider that decreasing patellofemoral pressure would be beneficial in pain control. In our study, the reason for measuring pressure by animal tests is that the knee joint is dynamic and that the knee could be affected not only by vector changes but also by muscular contractions. We noticed that in the literature, there was no biomechanical animal study about the effect of Maquet's procedure on patellofemoral pressure.

Our study aimed to evaluate biomechanically the patella pressure on femoral trochlea in an animal experiment by Maquet's procedure (anterior elevation of tuberositas tibia).

\section{Materials and methods}

\section{Experimental Design}

All animal studies were carried out with the approval of the Institutional Animal Care and Use Committee (Date and Decision no: 2010/810-10). Animals were housed at constant temperature (20-22oC) and humidity (50-60\%) with a 12-h light and 12-h dark cycle. They were allowed free access to water and standard rat chow.

This study included a total 42 knees of 21 New Zealand rabbits. In rabbits, it is well recognized that skeletal growth is completed at week 28 and reaches to mature adult height at week 34 . In respect of this information, animals used in the study were selected among rabbits older than 34 weeks and approximately with 1000$1200 \mathrm{~g}$ of weight.

Animals were assigned in two groups. The first group consisted from 21 right knees and surgery for the anterior elevation of tuberositas tibia was not applied, and only pressure measuring film layer "prescala" (Fujifilm, Japan) was placed on the patellofemoral joint (Control group). Second group consisted from 21 left knees. In the second group, anterior elevation of tuberositas tibia (Maquet's technique) was performed on left knees and pressure measuring film layer "prescala" 
(Fujifilm, Japan) was placed on patellofemoral joint LLW (Fujifilm, Japan) (super low pressure) $0.5-2.5 \mathrm{Mpa}$ was used as a film layer (MT Group).

\section{Anesthesia and Analgesia}

An injectable mixture of Ketamine- Xylazine was administered to animals for surgical anesthesia. The injection was performed into quadriceps muscle with the tip of syringe toward posterior to prevent sciatic nerve damage. The dose administered for ketamine and Xylazine was $35 \mathrm{mg} / \mathrm{kg}$ and $5 \mathrm{mg} / \mathrm{kg}$, respectively. During post-operative care, animals were kept alive and allowed to complete the healing process in a warm and dry and quiet area for 24 hours following the surgical procedure. Feeding was allowed as soon as the animals were awake to ensure gastrointestinal motility and prevent stasis. Ketoprofen $(5 \mathrm{mg} / \mathrm{kg}$, sc) was administered for post-operative analgesia and ciprofloxacin (10 $\mathrm{mg} / \mathrm{kg}, \mathrm{Po}$ ) was also administered within the first day following surgery as anti-biotic prophylaxis.

\section{Surgical Technique}

Preoperative preparations were done on 42 knees of 21 animals before the surgical procedure. For this purpose, knees were kept at extension, shaved and aseptic conditions were obtained by administration of antiseptic (Figure 1A). The midline skin incision was preferred as surgical technic, and then skin and subcutaneous tissue were dissected to the lateral and lateral part of patella and

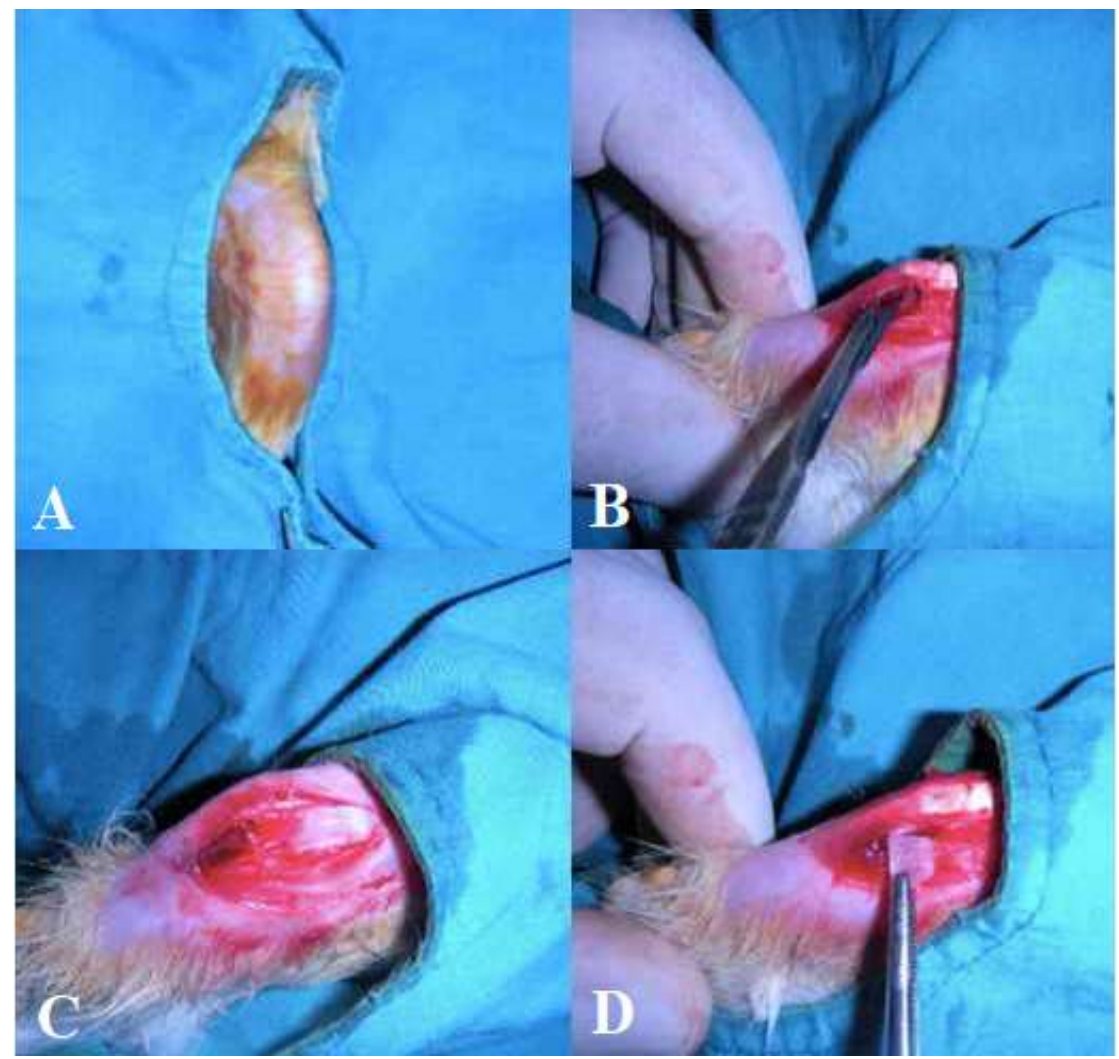

Figure 1. A) Pre-operative preparation of rabbit knee. B) Opening of knee joint by lateral approach and exposure of patellofemoral joint. C) Split elevation of tuberositas tibia. D) Anterior elevation of tuberositas tibia for $3 \mathrm{~mm}$ and placing sterile polyethylene wedge. 
retinaculum were exposed. The lateral patellarapproach was used for arthrotomy. Synovial tissue was incised at the lateral margin of the patella and lateral soft tissue providing patellar stability, was cut (Figure 1B). Maquet's procedure was not applied at the right knees of animals; only the patellofemoral groove was visualized.

Maquet's procedure was applied at left knees of animals. In technic described by Maquet in 1963, tuberositas tibia is anteriorly elevated for $2 \mathrm{~cm}$ as a split. Autologous bone graft is placed in between without tearing distal attachment [13]. In this study, tuberositas tibia of the left knee was raised as split and anteriorly elevated about $3 \mathrm{~mm}$ (In human, when tibia was raised about $30 \mathrm{~cm}$, anterior elevation is $2 \mathrm{~cm}$. we also measured rabbit tibia average $7 \mathrm{~cm}$ and proportionally we anteriorly elevated $3 \mathrm{~mm}$ ) and a sterile polyethylene wedge was placed in between (Figure 1C and D). Maquet's procedure was not applied at the right knee of animals; only the patellofemoral groove was visualized.

Following the surgical procedure, Fuji LLW pressure measuring "prescala" film layer cut as a trochlear groove, was placed in patellofemoral space of both knees. Joint capsule was sutured, and layers were closed regularly. Animals were monitored by a sterile dressing. Following 24 hours of rest after the procedure, film layers were measured by FPD8010E Fuji Film pressure measuring system.

LLW Fuji (Fujifilm, Japan) pressure measuring film layer used in our study is in the form of a trochlear groove. Higher pressure level was observed in certain area of each film layer compared to other areas. Therefore, the average pressure level to calculate total pressure on the whole film layer and maximal pressure on film layers were measured.

\section{Statistical analysis}

Data were analyzed using the IBM Statistical Package for Social Sciences v16 (SPSS Inc., Chicago, IL, USA). Parametric tests were applied to data of normal distribution, and nonparametric tests were applied to data of questionably normal distribution. Wilcoxon Signed Ranks Test was used to test the difference between pressures mean. Continuous data were presented as mean \pm standard deviation or median [minimum-maximum], as appropriate. All differences associated with a chance probability of 0.05 or less were considered statistically significant.

\section{Results}

Forth two knees of 21 New Zealand rabbits were evaluated. Totally 84 pressure level, including both two average pressure and maximal pressures, were obtained for both knees of 21 rabbits (Table 1). In our study, both average pressure and maximal pressure at rabbit knees subjected to Maquet's procedure were significantly lower than knees without Maquet procedure (Table 2,3). There is a statistically significant difference in terms of average pressure and maximum pressure between the right and left legs of the rabbits $(p<0.05)$.

\section{Discussion}

Our study aimed to evaluate biomechanically the patella pressure on femoral trochlea in an animal experiment by anterior elevation of tuberositas tibia which called Maquet's procedure. We revealed that Maquet's procedure could be suggested as successful in reducing targeted patellofemoral joint pressure to control AKP.

The patellofemoral joint consists of articulation between patella which has an irregular structure and trochlear groove. Contact pattern between 
Table 1. Pressure measurement in the study.

\begin{tabular}{|c|c|c|c|}
\hline \multicolumn{2}{|l|}{ Animals } & \multirow{2}{*}{ 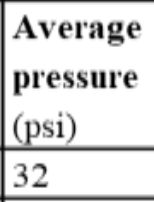 } & \multirow{2}{*}{$\begin{array}{l}\text { Maximum } \\
\text { pressure } \\
\text { (psi) }\end{array}$} \\
\hline Rabbit 1 & Right Knee & & \\
\hline & Left Knee & 31 & 61 \\
\hline \multirow[t]{2}{*}{ Rabbit 2} & Right Knee & 151 & 298 \\
\hline & Left Knee & 150 & 238 \\
\hline \multirow[t]{2}{*}{ Rabbit 3} & Right Knee & 134 & 287 \\
\hline & Left Knee & 94 & 221 \\
\hline \multirow[t]{2}{*}{ Rabbit 4} & Right Knee & 104 & 292 \\
\hline & Left Knee & 89 & 207 \\
\hline \multirow[t]{2}{*}{ Rabbit 5} & Right Knee & 87 & 195 \\
\hline & Left Knee & 52 & 131 \\
\hline \multirow[t]{2}{*}{ Rabbit 6} & Right Knee & 70 & 184 \\
\hline & Left Knee & 66 & 132 \\
\hline \multirow[t]{2}{*}{ Rabbit 7} & Right Knee & 104 & 259 \\
\hline & Left Knee & 64 & 228 \\
\hline \multirow[t]{2}{*}{ Rabbit 8} & Right Knee & 68 & 195 \\
\hline & Left Knee & 56 & 193 \\
\hline \multirow[t]{2}{*}{ Rabbit 9} & Right Knee & 139 & 230 \\
\hline & Left Knee & 136 & 214 \\
\hline \multirow[t]{2}{*}{ Rabbit 10} & Right Knee & 80 & 209 \\
\hline & Left Knee & 52 & 172 \\
\hline \multirow[t]{2}{*}{ Rabbit 11} & Right Knee & 78 & 192 \\
\hline & Left Knee & 56 & 164 \\
\hline \multirow[t]{2}{*}{ Rabbit 12} & Right Knee & 55 & 142 \\
\hline & Left Knee & 54 & 112 \\
\hline \multirow[t]{2}{*}{ Rabbit 13} & Right Knee & 81 & 131 \\
\hline & Left Knee & 74 & 105 \\
\hline \multirow[t]{2}{*}{ Rabbit 14} & Right Knee & 67 & 165 \\
\hline & Left Knee & 53 & 158 \\
\hline \multirow[t]{2}{*}{ Rabbit 15} & Right Knee & 72 & 172 \\
\hline & Left Knee & 70 & 165 \\
\hline \multirow[t]{2}{*}{ Rabbit 16} & Right Knee & 52 & 121 \\
\hline & Left Knee & 48 & 108 \\
\hline \multirow[t]{2}{*}{ Rabbit 17} & Right Knee & 63 & 75 \\
\hline & Left Knee & 60 & 62 \\
\hline \multirow[t]{2}{*}{ Rabbit 18} & Right Knee & 86 & 92 \\
\hline & Left Knee & 71 & 90 \\
\hline \multirow[t]{2}{*}{ Rabbit 19} & Right Knee & 123 & 165 \\
\hline & Left Knee & 114 & 147 \\
\hline \multirow[t]{2}{*}{ Rabbit 20} & Right Knee & 168 & 193 \\
\hline & Left Knee & 155 & 173 \\
\hline \multirow[t]{2}{*}{ Rabbit 21} & Right Knee & 48 & 61 \\
\hline & Left Knee & 46 & 59 \\
\hline
\end{tabular}

psi= pounds per inch square $(1$ psi $=0,068 \mathrm{~atm})$. RK: Right knee; LK: Left knee.
Table 2. Analysis table of both average and maximum pressure of knees subjected to Maquet technique.

\begin{tabular}{|l|l|l|l|}
\hline Parameters & N & Mean \pm SD & Min - Max \\
\hline $\begin{array}{l}\text { Right Average } \\
\text { pressure (psi) }\end{array}$ & 21 & $88.6 \pm 32.795$ & $32-168$ \\
\hline $\begin{array}{l}\text { Right Maximum } \\
\text { pressure (psi) }\end{array}$ & 21 & $177.4 \pm 64,36$ & $68-298$ \\
\hline $\begin{array}{l}\text { Left Average } \\
\text { pressure (psi) }\end{array}$ & 21 & $75.7 \pm 32,42$ & $31-155$ \\
\hline $\begin{array}{l}\text { Left Maximum } \\
\text { pressure (psi) }\end{array}$ & 21 & $149.5 \pm 51,34$ & $59-238$ \\
\hline
\end{tabular}

SD: Standard deviation.

Table 3. There is statistically significant difference between right and left limb of rabbits in respect of average pressure and maximum pressure.

\begin{tabular}{|l|l|l|}
\hline Parameters & $\begin{array}{l}\text { Average } \\
\text { pressure } \\
\text { right-left }\end{array}$ & $\begin{array}{l}\text { Maximum } \\
\text { pressure } \\
\text { right-left }\end{array}$ \\
\hline Z value & $-3,411(a)$ & $-3,411(a)$ \\
\hline $\begin{array}{l}\text { Asymp. Sig. } \\
\text { (2-tailed) }\end{array}$ & $0,001(\mathrm{~b})$ & $0,001(\mathrm{~b})$ \\
\hline
\end{tabular}

a: based on positive ranks; $b$ : Wilcoxon Signed Ranks Test.

the patella and trochlear groove changes during movement of the knee joint. According to the neuroanatomic studies, it is reported that the main factor of AKP is tension at lateral retinaculum which causes ischemic process thus forms neural proliferation at nosiseptive axons around vascular structures [14]. The main reasons for AKP have to be identified and after elimination of differential diagnosis "patellofemoral syndrome" can be diagnosed. Although the initial cause and pathogenesis of PFPS are not fully understood; many factors such as acute trauma, injury of knee ligament, instability, over-usage, genetic predisposition, impaired alignment of knee extensor 
mechanism may be responsible [6-8,15-18]. However, many authors consider the theory of increased patellofemoral pressure due to impairment of patellar alignment. Abnormal muscular and biomechanical factors are considered to change the relationship of the patella with femoral trochlear incisura and thus to increase patellofemoral pressure and lead to pain and dysfunction [19,20-22]. It is also reported that there are surgical methods as conservative methods in the treatment of PFPS. Distal realignment procedures including also Maquet's osteotomy, are demonstrated to have good results in the treatment of misalignment [23]. Shirazi-Adl et al. reported that patellofemoral contact forces decrease with Maquet's osteotomy at low flexion angles, but maximum contact forces increase at 90 degrees o flexion angle in the 3D model biomechanical study [24].

We aimed to evaluate whether this procedure leads to suggested pressure reduction. Thus, we could propose this technic as a safer method in the surgical treatment of cases with PFPS. The goal of this technic is pressure reduction; however, no analytical method could demonstrate the success of this technic. In a study conducted on ten knees from cadavers, the effect of tuberositas tibia straight anterior elevation technic on the pressure of patella on trochlea has been evaluated and a reduction of pressure for $20 \%$ to $23 \%$ was reported [25]. In 2000 , in a computer-modeled study of Farahmand et al., they reported that Maquet's procedure reduced patellofemoral pressure by $70 \%, 30 \%$ and $15 \%$ at extension, 30 degrees of flexion and 90 degrees of flexion, respectively [26]. In the literature, there are also studies comparing different technics of the osteotomy and measuring knee pressure [11,27]. In rabbit knee, the Maquet's procedure is more likely to apply compared to other osteotomy technics as the knee, in this case, is smaller. Although rabbit is a rodent and the knee is at flexion during rest, and it is unlikely to get objective data in an experimental study of knee biomechanics, it is sufficient for applying the technic and providing necessary vector changes.

We are aware that there are clear limitations of the case series presented here. Although the method of pressure measuring film layer used in this study is a quantitative and reliable method, deviations of measurements can occur due to the smaller size of rabbit knee and difficulties in shaping trochlea. Also, another limitation of the study is lack of expected muscular contractions level of rabbits during the post-operative period since the vectors necessary for patellofemoral pressure are due to muscular contractions. However, in our study, we can postulate that standard measurements could be obtained as we operated both knees of animals.

\section{Conclusions}

In our study where we used the other knee of the rabbit as control, we detected a significant pressure reduction of patellofemoral joints on knees subjected to Maquet's technique. In conclusion, in our study, Maquet's procedure can be suggested as successful in reducing targeted patellofemoral joint pressure to control AKP. Therefore, Maquet's osteotomy used commonly in the past can be still valid for today and can be safely used in any cases with PFPS non-responding to conservative treatment.

Funding: There is no financial support and sponsorship.

Conflict of Interest: The authors declare that they have no conflict of interest.

Ethical statement: All experiments were approved by the Ege University Animal 
Experiments Local Ethics Committee (Date and Decision no: 2010/810-10).

\section{Open Access Statement}

This is an open access journal which means that all content is freely available without charge to the user or his/her institution under the terms of the Creative Commons Attribution NonCommercial License

(http://creativecommons.org/licenses/bync/4.0). Users are allowed to read, download, copy, distribute, print, search, or link to the full texts of the articles, without asking prior permission from the publisher or the author.

\section{References}

[1]Boling M, Padua D, Marshall S, et al. Gender differences in the incidence and prevalence of patellofemoral pain syndrome. Scand J Med Sci Sports. 2010; 20(5):725-30.

[2]Gerbino PG. Adolescent anterior knee pain. Oper Tech Sports Med. 2006; 14(3):203-11.

[3]Fulkerson JP, Arent EA. Anterior knee pain in females. Clinc Orthop Relat Res. 2000;372:69-73.

[4]Tria AJ, Palumbo RC, Alicea JA. Conservative care for patellofemoral pain. Orthop Clin North Am. 1992; 23(4):545-54.

[5]Riva SR, Fitzgerald K, Irrgang JJ. Reability of measures of impairments associated with patellofemoral pain syndrome. BMC Musculoskeletal Disord. 2006; 7:33.

[6]Cutbill JW, Ladly KO, Bray RC, et al. Anterior knee pain: a review. Clin J Sports Med. 1997; 7(1):40-45.

[7]Natri A, Kannus P, Järvinen M. Which factors predict the long-term outcome in chronic patellofemoral pain syndrome? A 7yr prospective follow-up study. Med Sci Sports Exerc. 1998; 30(11):1572-77.
[8]Fulkerson JP. Diagnosis and treatment of patients with patellofemoral pain. Am Orthop Sports Med. 2002; 30(3):447-56.

[9]Petersen W, Ellermann A, GöseleKoppenburg A, et al. Patellofemoral pain syndrome. Knee Surg Sports Traumatol Arthrosc. 2014; 22(10):2264-74.

[10]Kuru I, Haberal B, Avcı C. "Patellofemoral biomechanics." TOTBID Journal. 2012; 11(4):274-80.

[11] Kim JH, Kim JR, Lee DH, et al. Combined medial open-wedge high tibial osteotomy and modified Maquet procedure for medial compartmental osteoarthritis and patellofemoral arthritis of the knee. Eur $\mathbf{J}$ Orthop Surg Traumatol. 2013; 23(6):679-83.

[12] Abdel Megied WS, Mahran MA, Thakeb MF, et al. The new "dual osteotomy": combined open wedge and tibial tuberosity anteriorisation osteotomies. Int Orthop. 2010; 34(2):231-37.

[13] Maquet P. A biomechanical treatment of femoro-patellar arthrosis: advancement of the patellar tendon. Rev Rhum Mal Osteoartic. 1963; 30:779-83.

[14] Miswan MF, Al-Fayyadh MZ, Seow Hui T, et al. Soft-tissue loop for medial patellofemoral ligament reconstruction. Arthrosc Tech. 2016; 5(2):e321-27.

[15] Stauffer RN. Disorders of the patellofemoral joint. Mayo Clinic Proceedings; 1990;65(10):P1390-91.

[16] Johnston LB, Gross MT. Effects of foot orthoses on quality of life for individuals with patellofemoral pain syndrome. J Orthop Sports Phys Ther. 2004; 34(8):440-48.

[17]Dixit S, DiFiori JP, Burton M, et al. Management of patellofemoral pain syndrome. Am Fam Physician. 2007; 75(2):194-202.

[18] Thomeé R1, Augustsson J, Karlsson J. Patellofemoral pain syndrome: a review of 
current issues. Sports Med. 1999; 28(4):24562.

[19]Crossley K, Bennell K, Gren S, et al. A systematic review of physical interventions for patellofemoral pain syndrome. Clin $\mathrm{J}$ Sports Med. 2001; 11(2):103-10.

[20] Grelsamer RP. Patellar malalignment. J Bone Joint Surg Am. 2000; 82(11):1639-50.

[21] Sheehan FT1, Derasari A, Brindle TJ, et al. Understanding patellofemoral pain with maltracking in the presence of joint laxity: complete 3D in vivo patellofemoral and tibiofemoral kinematics. J Orthop Res. 2009; 27(5):561-70.

[22] Song CY1, Lin JJ, Jan MH, et al. The role of patellar alignment and tracking in vivo: the potential mechanism of patellofemoral pain syndrome. Phys Ther Sport. 2011; 12(3):140-47.

[23]Longo UG, Rizzello G, Ciuffreda M, et al. Elmslie-Trillat, Maquet, Fulkerson, Roux Goldthwait, and other distal realignment procedures for the management of patellar dislocation: systematic review and quantitative synthesis of the literature. Arthroscopy. 2016; 32(5):929-43.

[24] Shirazi-Adl A, Mesfar W. Effect of tibial tubercle elevation on biomechanics of the entire knee joint under muscle loads. Clin Biomech (Bristol, Avon). 2007; 22(3):34451.

[25] Rue JP1, Colton A, Zare SM, et al. Trochlear contact pressures after straight anteriorization of the tibial tuberosity. Am J Sports Med. 2008; 36(10):1953-59.

[26]Farahmand F, Tahmasebi MN. Biomechanical analysis of the anterior displacement of tibial tuberosity (Maquet operation): A computer model study. Acta Medica Iranica. 2000; 38(1):61-66.

[27] Maugans CJ, Scuderi MG, Werner FW, et al. Tibial tubercle osteotomy: A biomechanical comparison of two techniques. Knee. 2017; 24(2):264-70. 